\title{
Information-Driven Framework for Collaborative Business Service Modelling
}

\author{
Thang Le Dinh, Université du Québec à Trois-Rivières, Canada \\ Thanh Thoa Pham Thi, Dublin City University, Ireland
}

\begin{abstract}
In the context of a network of enterprises, the competitive advantage of each enterprise depends greatly on the ability to use network architectures to collaborate efficiently in business services. The paper introduces a conceptual framework, called the CBSM (Collaborative Business Service Modelling) framework, which provides an intellectual foundation for understanding thoroughly and modelling effectively collaborative business services. The paper begins by presenting the necessity for and principles of the conceptual framework. Then it presents the architecture of the CBSM framework that consists of three different levels: the service level for service operation, the service system level for service creation, and the service value creation network level for service proposal. The paper continues with a discussion and review of the relevant literature, followed by the conclusion and suggestions for further research.
\end{abstract}

Keywords: $\quad$ Collaborative Business Services, Conceptual Framework, Service Modelling, Service Science, Service System, Service Value Creation Network

\section{INTRODUCTION}

Today, the service sector comprises $75 \%$ of the gross domestic product (GDP) of developed countries, dominating modern economies (Spohrer et al., 2007) and growing rapidly worldwide. Yet, there is still little research addressing the challenges of service design and innovation (Bitner et al., 2008).

Services mean opportunities, but enterprises that have been leading the charge still lack a strong foundation for their work. Therefore, it

DOI: $10.4018 /$ jssmet.2012010101 is important to develop a thorough understanding as well as innovative approaches, including new methods, models and frameworks for designing and managing services, in order to succeed in a competitive world (Chesbrough \& Spohrer, 2006).

On the other hand, the obligation to become more competitive and effective in providing better products and services requires enterprises to transform from traditional businesses into networked businesses. The availability of the Internet and information technologies has encouraged new business strategies that take advantage of enterprises' ability to create networks or to network with other enterprises. 
One of the challenges faced by a network of enterprises today is the integration of its members, which is highly correlated to the ability to use network architectures to collaborate efficiently in business services.

As a matter of fact, traditional methods of service design often focused on designing services inside an enterprise (Bitner et al., 2008). To our knowledge, there is little focus on service design in the context of a network. For this reason, our research focuses on providing a foundation for understanding, designing and managing collaborative business services in a network of enterprises.

This paper proposes a conceptual framework for understanding and modelling collaborative business services in a network of enterprises based on shared information, called the CBSM (Collaborative Business Service Modelling) framework. The main contribution of the paper is to provide concepts and guidelines to facilitate the use and adaptation of service description languages and models to different dimensions of collaborative business services.

This paper is structured as follows. First, the background and principles of the informationdriven approach are presented. The paper explains the CBSM framework for collaborative business service modelling at three levels: the service level for service operation, the service system level for service creation, and the service value creation network level for service proposal.An example of collaborative business services in a travel and tourism network is explored. The paper continues with a discussion and review of the literature, followed by the conclusion and suggestions for future research.

\section{BACKGROUND}

This section provides the definition and characteristics of different aspects of service science that serve as the background for current research in business service design.

\section{Service Science, Management and Engineering}

The service economy refers to the service sector, which has become the most important economic sector, surpassing traditional sectors such as agriculture and manufacturing (Lusch et al., 2008). As the dominant role of the service sector has become obvious, there is a need for a new science of service systems, which aims to increase service innovation by applying scientific understanding, engineering discipline and management practices to understanding and working with service systems (Maglio et al., 2008).

Service Science, Management, and Engineering (SSME) is a term used to describe service science as a trans-disciplinary approach to the study, design, and implementation of service systems (Spohrer et al., 2007; Maglio et al., 2008). SSME is comprised of three elements: science, management and engineering. The science component deals with the structure of service systems and clarifies the process of service creation and the application of competencies in an economic entity for the benefit of other entities. The management component concerns techniques to improve business services through effective management. The engineering component covers the invention of new technologies to improve the quality of existing business services and create new, innovative ones.

\section{Service Value Creation Network}

The service economy is based on a new servicedominant logic, as distinct from the traditional goods-dominant logic (Lusch et al., 2008). In service-dominant logic, services are defined as the use of an economic entity's specific competencies, such as knowledge, skills and technologies, to benefit another economic entity (Vargo \& Lusch, 2004). In this situation, value creation occurs when a resource is turned into a specific benefit. This activity, performed by a service system, is called resourcing. 
16 more pages are available in the full version of this document, which may be purchased using the "Add to Cart"

button on the publisher's webpage:

www.igi-global.com/article/information-driven-frameworkcollaborative-business/68789

\section{Related Content}

How to Market OR/MS Decision Support

Masayuki Ueda (2010). Service Science and Logistics Informatics: Innovative

Perspectives (pp. 157-172).

www.irma-international.org/chapter/market-decision-support/42641/

Customers as Innovators in Senior Service Markets: An Examination of Innovation Potential and Characteristics

Lea Hennala, Helinä Melkas and Satu Pekkarinen (2013). Best Practices and New

Perspectives in Service Science and Management (pp. 31-53).

www.irma-international.org/chapter/customers-innovators-senior-service-

markets/74985/

A Service Science Perspective on Human-Computer Interface Issues of Online Service Applications

Claudio Pinhanez (2009). International Journal of Information Systems in the Service

Sector (pp. 17-35).

www.irma-international.org/article/service-science-perspective-human-

computer/2526/

Knowledge Transfer in Product-Based Service Design

Naoshi Uchihira (2014). Progressive Trends in Knowledge and System-Based

Science for Service Innovation (pp. 258-272).

www.irma-international.org/chapter/knowledge-transfer-in-product-based-

service-design/87926/

A 3D Vision-Based Solution for Product Picking In Industrial Applications Mirko Sgarbi, Valentina Colla and Gianluca Bioli (2010). Intelligent Systems in Operations: Methods, Models and Applications in the Supply Chain (pp. 190-208). www.irma-international.org/chapter/vision-based-solution-product-

picking/42661/ 